JOURNAL OF APPLIED CRYSTALLOGRAPHY

ISSN 1600-5767

Keywords: book reviews.

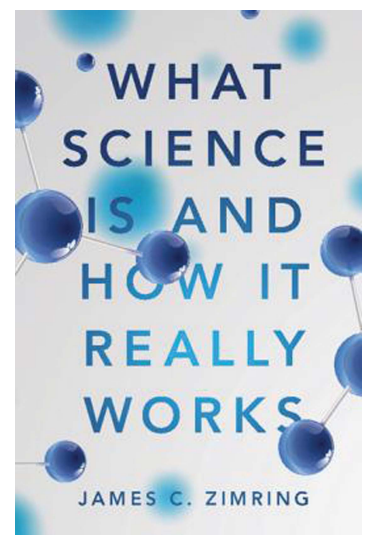

(C) 2019 International Union of Crystallography

\section{What Science Is and How It Really Works. By James C. Zimring. Cambridge University Press, 2019. Pp. 402. Price USD 25.99. Paperback ISBN 9781108701648.}

\author{
John R. Helliwell*
}

Department of Chemistry, University of Manchester, Manchester M13 9PL, UK. *Correspondence e-mail: john.helliwell@manchester.ac.uk

This book contains both topical and historical material neatly describing current issues such as the R. A. Fisher $P=0.05$ scientific proof test (Fisher 1935) as well as case studies drawn largely from the author's own impressive scientific background in immunology and medical and clinical research. The author is based in the USA. This may not seem immediately relevant to my review, but since he quotes (p. 261) a 2005 survey of the US public revealing that 'three out of every four Americans believe in the paranormal' this presumably explains why a large number of the author's examples and case stories describe, then dismiss as unscientific, spiritualist medium tales and ESP (extra sensory perception) 'proof experiments'. These case stories seem to form a large fraction of the first half of the book, whereas what I would call the more serious content is in the latter half. That said, the penultimate chapter also discusses astrology, the soul and vitalism. The author does explain his approach by stating that the best way to demonstrate what science really is about is by dissecting the unscientific. This I found rather tedious, like explaining antisocial behaviour to lay a grounding for what one would then describe as good social behaviour. Suffice to say, I think that was the wrong approach. The book even states that (p. 74) 'science is inferior to religion as an explanation of experience'. At which point Richard Feynman's sharp insight sprang to my mind, that 'religion is a culture of faith and science is a culture of doubt'.

Let's now focus on the declared content, whose chapter headings are promising:

\section{Introduction}

1. The knowledge problem, or what we can really 'know'?

2. Adding more building blocks of human reasoning to the knowledge problem

3. Holistic coherence in thinking, or describing a system of how humans reason and think

4. How scientific reasoning differs from other reasoning

5. Natural properties of a rule-governed world, or why scientists study certain types of things and not others

6. How human observation of the natural world can differ from what the world really is

7. Detection of patterns and associations, or how human perceptions and reasoning complicate understanding of real-world information

8. The association of ideas and causes, or how science figures out what causes what

9. Remedies that science uses to compensate for how humans tend to make errors

10. The analysis of a phantom apparition, or has science really been studied yet?

11. The societal factor, or how social dynamics affect science

12. A holistic world of scientific entities, or considering the forest and the trees together

13. Putting it all together to describe 'What science is and how it really works'

The headings seem to feature problems and errors of science and knowledge, but the word 'success' is not mentioned. I also compared the above contents list with the book's web site at Cambridge University Press. A key statement made there is 'Crucial in our political climate, the book fights the myths of science often portrayed to the public.' I find a heavy preponderance of paranormal case studies a strange way to fight myths.

But let's try and focus on the positives of the book. Science as a process, as the author correctly states, involves the individual scientist, societies of scientists and a web of belief (what I would call the growing corpus of knowledge). Individuals can make striking 
contributions. Several are lauded. The $P=0.05$ statistical confidence test, first introduced by Sir Ronald Fisher (1935), is excellently described and made accessible by detailing a repeated coin tossing test. Once the probability of making an error of $5 \%$ is crossed (i.e. $5 \%$ or lower probability), a hypothesis can be deemed proved as not occurring by chance, as summarized by Table 9.1 on p. 252. Zimring reiterates the current controversy about this test but with a neat example of a clinical drug trial test which does not reach the threshold of $5 \%$ or lower but is, say, $6 \%$. What if it was a potentially useful drug but was deemed unproven according to the standard Fisher $P=0.05$ test? As the author points out, it is obviously interesting that Fisher proposed a test and that the community of scientists of the time and since, until recently, have accepted the wisdom of having such a relatively simple threshold-ofproof test. Fisher also proved to be a figure of further interest in the history of science as he apparently argued over many years that smoking does not cause cancer but that cancer causes smoking. Furthermore, the health data available could not actually discriminate one versus the other, he argued.

There are a couple of specific concerns I would lodge. In developing his description of what science really is, Zimring discusses at length 'Hempel's black raven paradox' (p. 67). This involves the logic of considering, for example, that an apple being green has some influence, albeit tiny according to the paradox but not zero, in establishing that ravens are black. This reminded me of the joke about the tourist asking the way to a place and the local resident stating in reply 'well if I was going there I wouldn't start from here'. The second concern is that, as crystallographers, we would of course take issue with the author's statement on p. 64 that 'No scientist has ever directly observed an atom.' However, there are undoubted strengths to the book, such as the author's various historical accounts of science as a process and its evolution as a process. $\mathrm{He}$ also gives nice up-to-date examples of curiosity-driven science and how this has led to applications in gene editing and autoimmunity.

So, would I recommend the book? I could recommend a second edition where the paranormal case stories are removed. Also some more content about the power of knowledge and successes of science would be fair and appropriate too, for the public at large especially, who might one day just take their health, wealth and comfort for granted and as tax payers deny science funding agencies their future funds. This is a serious matter not to be toyed with.

On p. 379, the author provides his answers to the question in the book's title: 'In short, science is a seriously flawed enterprise, with numerous sources of error at multiple levels'. In my own book (Helliwell, 2019) I also give my answer as to what science is, namely scientific truth is uncertainty, be it at the quantum level or in errors of our measurements. So on that we agree. But in addition it is vital to recognize, I think, that science and its objectivity as a process is not about the narrative but is in the experimental data.

\section{References}

Fisher, R. A. (1935). The Design of Experiments. Edinburgh: Oliver and Boyd.

Helliwell, J. R. (2019). The Whats of a Scientific Life. In the press. Boca Raton: CRC Press/Taylor and Francis. 